\title{
The role of behavior change communication on knowledge and uptake of postpartum contraception among antenatal mothers in Puducherry: a randomized controlled trial
}

\author{
Neelima S. Chauhan ${ }^{1 *}$, Agnes Mathew ${ }^{2}$
}

\begin{abstract}
${ }^{1}$ Department of Obstetrics and Gynecology, Prasad Institute of Medical Sciences, Lucknow, Uttar Pradesh, India ${ }^{2}$ Department of Obstetrics and Gynecology, Al- Azhar Medical College, Idduki, Kerala, India
\end{abstract}

Received: 25 February 2020

Accepted: 27 March 2020

\author{
*Correspondence: \\ Dr. Neelima Singh Chauhan, \\ E-mail: drneelimasingh30@gmail.com
}

Copyright: () the author(s), publisher and licensee Medip Academy. This is an open-access article distributed under the terms of the Creative Commons Attribution Non-Commercial License, which permits unrestricted non-commercial use, distribution, and reproduction in any medium, provided the original work is properly cited.

\begin{abstract}
Background: India accounts for world's 17.5 percent population and is the second most populous country in the world next only to China (19.4\%). Birth control pills, condoms, sterilization, IUD (intrauterine device) etc. are most commonly practiced family planning methods in India. The latest NFHS shows that $77 \%$ of sterilized women did not use a family planning method. Despite of family welfare program having a target free approach, the program has not been successful in educating people about the concept and advantages of contraceptive methods for spacing births.

Methods: This randomized controlled trial was carried out in the department of obstetrics and gynecology of Pondicherry Institute of Medical Sciences (PIMS), Puducherry. All antenatal mothers $>28$ weeks of gestational age were enrolled and given a semi-structured questionnaire. After randomization intervention was done in the form of counselling and distribution of pamphlets for future use. The women were followed in the postnatal period and 6 weeks later.

Results: A total of 280 subjects were enrolled in this study. Socio-demographic characteristics were similar in both the study groups. Majority of women in both the comparison and intervention group were in the age group 20-25 years $(43.6 \%)$. Very few participants $(20.0 \%)$ had used some form of contraception to delay pregnancy. However, the postpartum follow-up of the study participants revealed significant increase in the knowledge on the various contraceptive methods in the intervention group compared with the comparison group.

Conclusions: The implementation of behaviour change communication strategy to communicate the benefits of uptake of postpartum contraception to antenatal mothers, is vital in improving the acceptability of family planning programs in India.
\end{abstract}

Keywords: Attitude, Family planning, Knowledge, Post-partum contraception, Practices

\section{INTRODUCTION}

India accounts for world's 17.5 percent population and is the second most populous country in the world next only to China (19.4\%). As on $1^{\text {st }}$ March, 2011 India's population stood at 1.21 billion. In simple terms, the population of India has increased by more than 181 million during the decade 2001-2011. ${ }^{1}$ The Indian
Government is one of the first in the world to launch a National family welfare programme.

Birth control pills, condoms, sterilization, IUD (Intrauterine device) etc. are most commonly practiced family planning methods in India. The efforts of the Government in implementing the family welfare programme in the country have had some impact on 
population control. However, social factors like illiteracy, reluctance, traditions and socio-cultural beliefs towards large family are some of the major constraints towards adopting family planning methods. Childbearing at a very young age, short birth intervals, status of women, strong son preference, and lack of male involvement in family planning, are also significant factors contributing against adoption of small family norm. These are associated with an increased risk of complications during pregnancy and childbirth and higher rates of neonatal mortality.

The latest NFHS shows that $77 \%$ of sterilized women did not use a family planning method. Despite of Family Welfare Program having a target free approach, the program has not been successful in educating people about the concept and advantages of contraceptive methods for spacing births. ${ }^{2}$

Puducherry is a Union territory with female literacy rate of $85.1 \%$. According to NFHS (2015-2016), female sterilization was the most common method adopted by the females in Puducherry which was $58.0 \%$. Use of pills and condoms as a method of birth spacing was $<1.0 \%$. Regarding quality of family planning services only $35.2 \%$ of the time a health worker has ever talked to female nonusers about family planning. ${ }^{2}$

This study was conducted to assess the change in knowledge attitude and practices of antenatal mothers about postnatal contraception following intervention.

\section{METHODS}

This randomized controlled trial was carried out in the department of Obstetrics and Gynecology of Pondicherry Institute of Medical Sciences (PIMS), Puducherry, India. The study protocol was approved by the Institute Ethics Committee of PIMS. (IEC:RC/13/121).

Taking the uptake of contraception in the postnatal period as $30 \%$, a sample size of 280 was calculated. All antenatal mothers of gestational Age 28 weeks or more who were willing to participate were enrolled. Those mothers who were $<28$ weeks, reported as emergency case or refused to participate for any reason were excluded from the study.

The eligible candidates coming for routine antenatal check-up in the outpatient department were given a prevalidated, semi-structured questionnaire to collect the data. The questionnaire administered included questions about socio-demographic status, fertility history including total no. of children, knowledge of different contraceptive methods and the source of knowledge, methods of contraception used before the current pregnancy. Randomization was done using block randomization technique. Intervention in the form of counselling and pamphlets was done in the intervention group where the mothers were explained in-depth about various methods of birth spacing and control, benefits of a small family and disadvantages of having pregnancies at short interval. Pictorial demonstration of various family planning methods was done using pamphlets which was handed over to the mother for future reference. A post test was conducted at the time of discharge (3-7 days after the delivery) using the same questionnaire. The mothers were followed up till 6 weeks postpartum. (Figure 1).

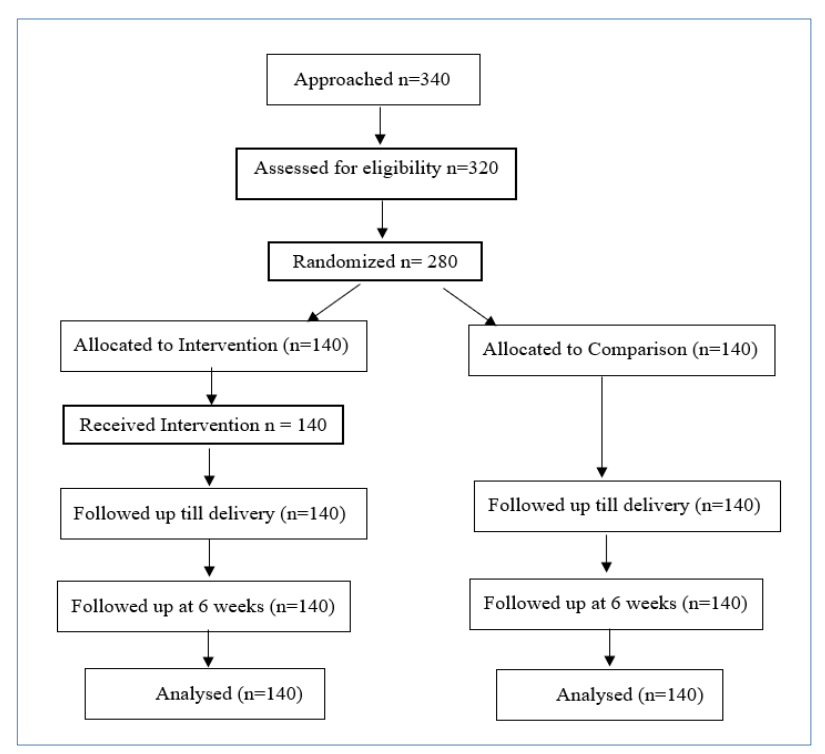

Figure 1: Randomization and follow-up of study subjects.

Women with no living children were coded as parity zero and those with one living child were coded as parity one.

\section{Statistical analysis}

Data entry was done in Microsoft excel spread sheet 2007 and analyzed in SPSS version 17.

\section{RESULTS}

A total of 280 subjects were enrolled in this study. Sociodemographic characteristics were similar in both the study groups. Majority of women in both the comparison and intervention group were in the age group 20-25 years $(47.9 \%, 39.3 \%)$. Regarding occupation most of the women were unskilled in both the study groups $(90.7 \%$, $89.3 \%)$. While majority of the husbands were semiskilled $(44.3 \%, 40.7 \%)$. Sixty-six percent of the women interviewed belonged to parity one. The family structure was also similar in both the study groups (Table 1).

Very few participants $(20.0 \%)$ had used some form of contraception to delay pregnancy. Watching family planning messages on television was the main source of information $(57.9 \%)$. And majority $(57.1 \%)$ of the study participants acknowledged the fact that they will consult their husbands regarding any form of contraceptive use to delay pregnancy (Table 2). 
Table 1: Socio-demographic characteristics of the study participants.

\begin{tabular}{|c|c|c|c|}
\hline Topic & $\begin{array}{l}\text { Comparison group } \\
\mathrm{N}=\mathbf{1 4 0}(\%)\end{array}$ & $\begin{array}{l}\text { Intervention group } \\
\mathrm{N}=140(\%)\end{array}$ & $\begin{array}{l}\text { Total } \\
\mathbf{N}=\mathbf{2 8 0}(\%)\end{array}$ \\
\hline \multicolumn{4}{|l|}{ Age (years) } \\
\hline $20-25$ & $67(47.9 \%)$ & $55(39.3 \%)$ & $122(43.6 \%)$ \\
\hline $26-30$ & $54(38.6 \%)$ & $61(43.6 \%)$ & $115(41.1 \%)$ \\
\hline \multicolumn{4}{|c|}{ Wife occupation } \\
\hline Unskilled & $127(90.7 \%)$ & $125(89.3 \%)$ & $252(90.0 \%)$ \\
\hline Semiskilled & $5(3.6 \%)$ & $2(1.4 \%)$ & $7(2.5 \%)$ \\
\hline Skilled & $5(3.6 \%)$ & $5(3.6 \%)$ & $10(3.6 \%)$ \\
\hline Professional & $3(2.1 \%)$ & $8(5.7 \%)$ & $11(3.9 \%)$ \\
\hline \multicolumn{4}{|c|}{ Husband occupation } \\
\hline Unskilled & $40(28.6 \%)$ & $40(28.6 \%)$ & $80(28.6 \%)$ \\
\hline Semiskilled & $62(44.3 \%)$ & $57(40.7 \%)$ & $119(42.5 \%)$ \\
\hline Skilled & $27(19.3 \%)$ & $25(17.9 \%)$ & $52(18.6 \%)$ \\
\hline Professional & $11(7.9 \%)$ & $18(12.9 \%)$ & $29(10.4 \%)$ \\
\hline \multicolumn{4}{|l|}{ Parity } \\
\hline Zero & $30(21.4 \%)$ & $20(14.3 \%)$ & $50(17.9 \%)$ \\
\hline One & $91(65.0 \%)$ & $96(68.6 \%)$ & $187(66.8 \%)$ \\
\hline Two & $18(12.9 \%)$ & $22(15.7 \%)$ & $40(14.3 \%)$ \\
\hline Three & $1(0.7 \%)$ & $2(1.4 \%)$ & $3(1.1 \%)$ \\
\hline \multicolumn{4}{|c|}{ Family structure } \\
\hline Joint & $63(45.0 \%)$ & $59(42.1 \%)$ & $122(43.6 \%)$ \\
\hline Nuclear & $77(55.0 \%)$ & $81(57.9 \%)$ & $158(56.4 \%)$ \\
\hline
\end{tabular}

Table 2: Practice of contraceptive use before antecedent pregnancy.

\begin{tabular}{|llll|}
\hline Use & $\begin{array}{c}\text { Comparison group } \\
\mathbf{N}=\mathbf{1 4 0}(\%)\end{array}$ & $\begin{array}{l}\text { Intervention group } \\
\mathbf{N}=\mathbf{1 4 0}(\%)\end{array}$ & $\begin{array}{l}\text { Total } \\
\mathbf{N}=280(\%)\end{array}$ \\
\hline Yes & $29(20.7 \%)$ & $28(20.0 \%)$ & $57(20.4 \%)$ \\
\hline No & $111(79.3 \%)$ & $112(80.0 \%)$ & $223(79.6 \%)$ \\
\hline Source of information & & & $35(12.5 \%)$ \\
\hline Newspaper & $21(15.0 \%)$ & $14(10.0 \%)$ & $23(8.2 \%)$ \\
\hline Radio & $11(7.9 \%)$ & $12(8.6 \%)$ & $162(57.9 \%)$ \\
\hline Television & $77(55.0 \%)$ & $85(60.7 \%)$ & $35(12.5 \%)$ \\
\hline Neighbours & $15(10.7 \%)$ & $20(14.3 \%)$ & $25(8.9 \%)$ \\
\hline Health professionals & $16(11.4 \%)$ & $9(6.5 \%)$ & $160(57.1 \%)$ \\
\hline Consultation regarding contraceptive use & & $6(2.1 \%)$ \\
\hline Husband & $83(59.3 \%)$ & $77(55.0 \%)$ & $19(6.8 \%)$ \\
\hline Mother in law & $3(2.1 \%)$ & $3(2.1 \%)$ & $95(34.0 \%)$ \\
\hline Mother & $9(6.4 \%)$ & $10(7.1 \%)$ & $5(35.7 \%)$ \\
\hline Doctor & $45(32.1 \%)$ & & \\
\hline
\end{tabular}

Table 3: Percentage of women having correct knowledge of contraceptive methods in postpartum period by study group.

\begin{tabular}{|lllll|}
\hline $\begin{array}{l}\text { Characteristics } \\
\text { Traditional methods }\end{array}$ & $\begin{array}{l}\text { Comparison group } \\
(\mathbf{N}=\mathbf{1 4 0})(\%)\end{array}$ & $\begin{array}{l}\text { Intervention group } \\
(\mathbf{N}=\mathbf{1 4 0})(\%)\end{array}$ & Total $(\mathbf{N}=\mathbf{2 8 0})(\%)$ & $\begin{array}{l}\text { Chi-square (df), } \mathbf{p} \\
\text { value }\end{array}$ \\
\hline Unsafe period & $54(38.6 \%)$ & $92(65.7 \%)$ & $146(52.1 \%)$ & $20.6(1), 0.00$ \\
\hline Rhythm method & $31(22.1 \%)$ & $70(50.0 \%)$ & $101(36.1 \%)$ & $23.5(1), 0.00$ \\
\hline Withdrawl method & $31(22.1 \%)$ & $57(40.7 \%)$ & $88(31.4 \%)$ & $11.2(1), 0.01$ \\
\hline LAM & $63(45.0 \%)$ & $103(73.6 \%)$ & $166(59.3 \%)$ & $23.6(1), 0.00$ \\
\hline Permanent methods & & & & $6.13(1), 0.01$ \\
\hline Female sterilization & $134(95.7 \%)$ & $140(100 \%)$ & $274(97.9 \%)$ & 6 \\
\hline
\end{tabular}




\begin{tabular}{|c|c|c|c|c|}
\hline Characteristics & $\begin{array}{l}\text { Comparison group } \\
(\mathrm{N}=140)(\%)\end{array}$ & $\begin{array}{l}\text { Intervention group } \\
(\mathrm{N}=140)(\%)\end{array}$ & Total $(\mathrm{N}=280)(\%)$ & $\begin{array}{l}\text { Chi-square (df), } p \\
\text { value }\end{array}$ \\
\hline Male sterilization & $105(75.0 \%)$ & $129(92.1 \%)$ & $234(83.6 \%)$ & $14.9(1), 0.00$ \\
\hline \multicolumn{5}{|c|}{ Modern temporary methods } \\
\hline Pills & $94(67.1 \%)$ & $131(93.6 \%)$ & $225(80.4 \%)$ & $30.9(1), 0.00$ \\
\hline IUCD & $85(60.7 \%)$ & $135(96.4 \%)$ & $220(78.6 \%)$ & $53.0(1), 0.00$ \\
\hline Injectables & $24(17.1 \%)$ & $75(53.6 \%)$ & $99(35.4 \%)$ & $40.6(1), 0.00$ \\
\hline Condom & $116(82.9 \%)$ & $135(96.4 \%)$ & $251(89.6 \%)$ & $13.8(1), 0.00$ \\
\hline Emergency contra & $31(22.1 \%)$ & $88(62.9 \%)$ & $119(42.5 \%)$ & $47.8(1), 0.00$ \\
\hline
\end{tabular}

Table 4: Uptake of any type of contraceptive method in the postpartum period.

\begin{tabular}{|c|c|c|c|c|}
\hline & $\begin{array}{l}\text { Comparison group } \\
(\mathrm{N}=140)(\%)\end{array}$ & $\begin{array}{l}\text { Intervention group } \\
(\mathrm{N}=140)(\%)\end{array}$ & Total $(\mathbf{N}=\mathbf{2 8 0})(\%)$ & $\begin{array}{l}\text { Chi-square (df), } p \\
\text { value }\end{array}$ \\
\hline Uptake of any method & $46(32.1 \%)$ & $49(35.0 \%)$ & $95(33.1 \%)$ & $0.143(1), 0.705$ \\
\hline
\end{tabular}

The postpartum follow-up of the study participants revealed significant increase in the knowledge on the various contraceptive methods in the intervention group compared with the comparison group (Table 3). However, this did not translate into practice as the uptake of contraceptive method in the immediate postpartum period and at 6 weeks postpartum was similar in both the comparison and intervention group (Table 4).

\section{DISCUSSION}

The current study was undertaken to test a comprehensive, hospital-based behavior change communication intervention for its effectiveness in educating pregnant women about postpartum contraception. The intervention included educational materials and counselling of antenatal women about benefits of limiting and spacing her pregnancies which has a direct impact on her health and well- being. The strategy was feasible and effective, as there was significant increases in the proportion of women who were aware of different contraceptive methods, risks and benefits at the end of the study. However, few of them adopted the method which was almost similar in both the comparison and intervention groups.

Do and Hotchkiss conducted a study to examine the associations between the use of maternal health care (specifically ANC and PNC services) and post-partum modern FP practice in Kenya and Zambia. They concluded that there was positive association between the intensity of ANC and PNC services and post-partum use of modern contraception. The more intensively women used ANC and PNC services, the more likely they go on to adopt a modern method of contraception after the index childbirth. ${ }^{3}$

In this study there was no significant association found between education, occupation of both husband and wife, parity, age of the women and use of postpartum contraception. Religion was the only parameter which had a positive association $(\mathrm{p}=0.03)$. It was seen that
Hindu women were more likely to opt for family planning method as compared to women belonging to another religion. Only 57 (20.4\%) had ever used some form of family planning in the past. Similar study done by Sherpa et al observed that, majority of 52 (38.23\%) had never used contraceptive methods and level of education did not play an important role in practice of family planning methods. ${ }^{4}$

In an RCT conducted in Nepal to evaluate impact of postnatal health education for mothers on postnatal family planning practices, the researchers found that slight improvement was observed in uptake of family planning at 6 months in groups who had health education intervention given on two occasions, immediately after delivery and 3 months later. ${ }^{5}$ In this study although there was overall increase in uptake of postpartum family planning method $(33.1 \%)$ but there was no significant difference in the group which received health education.

In a cross-sectional study conducted in Indonesia among pregnant women visiting primary health center, $86.53 \%$ were aware of at least one family planning method. Injectable was the best-known method of contraception. Majority $(63.3 \%)$ of them attributed their source of contraceptive information to health professionals. The findings were in contrast to our findings where television was an important source of information (57.9\%), and very few knew about injectable contraception (17.1\%). However, in both the studies husbands were the most popular persons to discuss the method of contraception with $(68.69 \% ; 57.1 \%){ }^{6}$

The Urban health initiative, funded by Bill and Melinda Gates Foundation (BMGF), was implemented in India to increase the modern contraceptive prevalence rate (mCPR). In this initiative community health workers (CHWs) visited every home in slums of target cities to offer information about FP methods and counsel on postpartum FP using street plays, road shows and mass media communication in order to promote demand for FP services, and integrate FP services with postpartum 
services. ${ }^{7}$ Achyut et al evaluated the impact of UHI and found that by the end of the study there was greater modern method use (54\%) and traditional method use had declined slightly $(13 \%)$. Female sterilization remained the most dominant method of FP. In addition, the study found borderline significance for being exposed to FP messages on the television (marginal effect: 2.46, $\mathrm{p}=0.001)^{8}$

Similar findings were found in a study conducted in Nigeria in which participants were randomized into antenatal and postnatal groups. The intervention was evaluated and it was found that women who received antenatal counseling sessions used significantly more modern contraceptive methods than those who received a postnatal counseling session (57\% compared to $35 \%$; $\mathrm{p}=0.002) .{ }^{9}$ Although very few randomized controlled trials have been done in India to evaluate the most effective and feasible method to increase the uptake of family planning methods and population control. However observational studies done, point to the fact that antenatal counselling regarding family planning methods is effective and feasible in increasing the uptake of postpartum contraception. ${ }^{10-13}$

\section{CONCLUSION}

Although use of contraceptive prevalence is increasing in India, contributing to decline in total fertility but its use is primarily to limit fertility rather than to control early childbearing and lengthen birth intervals. The implementation of behaviour change communication strategy to communicate the benefits of uptake of postpartum contraception to antenatal mothers, is vital to improving the acceptability of family planning programs in India.

\section{ACKNOWLEDGMENTS}

Authors would like to thank to all antenatal mothers who participated in the study. Authors would also like to thank the college and the hospital where the study was conducted.

Funding: No funding sources Conflict of interest: None declared

Ethical approval: The study was approved by the Institutional Ethics Committee

\section{REFERENCES}

1. Ministry of Home Affairs, Government of India, Census data, 2011. Available at: http://www.censusindia.gov.in/Census_Data_2011/Indi a_at_glance/popu1.aspx. Accessed on $24^{\text {th }}$ October 2018 .

2. International Institute for Population Sciences (IIPS) and ICF. 2017. National Family Health Survey (NFHS4), 2015-16: India. Mumbai: IIPS. Available at: http://www.rchiips.org/nfhs/nfhs3.shtml. Accessed on $24^{\text {th }}$ October 2018.

3. Do and Hotchkiss: Relationships between antenatal and postnatal care and post-partum modern contraceptive use: evidence from population surveys in Kenya and Zambia. BMC Health Serv Res. 2013;13:6.

4. Sherpa SZ, Sheilini M, Nayak. A Knowledge attitude practice and preferences of contraceptive methods in Udupi District, Karnataka. J Family Reprod Health. 2013;7(3):115-20.

5. Bolam A, Manandhar DS, Shrestha P, Ellis M, Costello AM. The effects of postnatal health education for mothers on infant care and family planning practices in Nepal: a randomized controlled trial. BMJ. 1998;316(7134):805-11.

6. Santoso BI, Surya R. Knowledge, attitude and practice of contraception among pregnant women in Ende District, East Nusa Tenggara, Indonesia. J South Asian Feder Obst Gynae. 2017;9(2):110-8.

7. Ministry of Health and Family Welfare, Government of India. Urban Health Mission. Available at: http://nrhm.gov.in/nhm/nuhm.html. Accessed on $20^{\text {th }}$ October 2015).

8. Achyut P, Benson A, Calhoun LM, Corroon M. Impact evaluation of the Urban Health Initiative in urban Uttar Pradesh, India. Contracept. 2016;93:519-25

9. Adanikin AI, Onwudiegwu U, Loto OM. Influence of multiple antenatal counselling sessions on modern contraceptive uptake in Nigeria. Eur $\mathrm{J}$ Contracept Reprod Health Care. 2013;18(5):381-7.

10. Sharma V, Mohan U, Das V, Awasthi S. Socio demographic determinants and knowledge, attitude, practice: survey of family planning. J Family Med Prim Care. 2012;1(1):43-7.

11. Prusty RK. Use of contraceptives and unmet need for family planning among tribal women in India and selected hilly states. J Health Popul Nutr. 2014;32(2):342-55.

12. Alsaedi JA, Alakel SM, Alalmaei AZ. Assessment of knowledge, attitude and practice towards family planning in Saudi Arabia. The Egypt J Hosp Med. 2018:70(2):345-8.

13. Amen W, Ahmed M. Effect of innovative contraceptive program on family planning utilization rate in Khartoum, Sudan: a randomized controlled trial. Gulf Med J. 2016;5(1):41-7.

Cite this article as: Chauhan NS, Mathew A. The role of behavior change communication on knowledge and uptake of postpartum contraception among antenatal mothers in Puducherry: a randomized controlled trial. Int J Reprod Contracept Obstet Gynecol 2020;9:2024-8. 